\title{
Transient Catabolic State with Reduced IGF-I after Antenatal Glucocorticoids
}

\author{
JOHAN VERHAEGHE, FLORENT VANSTAPEL, RITA VAN BREE, ERIK VAN HERCK, AND WILLY COOPMANS
}

\begin{abstract}
Department of Obstetrics and Gynecology [J.V., R.B.], Department of Laboratory Medicine [F.V.], Laboratorium voor Experimentele Geneeskunde en Endocrinologie [E.H., W.C.], Health Campus Gasthuisberg, Katholieke Universiteit Leuven, 3000 Leuven, Belgium
\end{abstract}

\begin{abstract}
Glucocorticoid (GC) administration before preterm birth reduces neonatal morbidity but may restrain growth. Here we explored the effect of antenatal GC on nutrient substrates [glucose, FFA, amino acids (AA)], and on IGF-I and IGF-binding protein-1 (IGFBP-1). We analyzed umbilical vein (UV) plasma obtained at birth from 91 preterm newborns that received one course of GC (last exposure 1-1358 h before birth) and 49 newborns that did not. We found that recent GC exposure ( $\leq 48 \mathrm{~h}$ ) raised glucose, FFA, and AA concentrations, and the homeostasis model assessment of insulin resistance (HOMA-IR) index, but lowered IGF-I concentrations. The AA surge was greater in newborns with a birth weight $z$ score $<0$ than in those with a $z$ score $>0$. Although all AA were transiently increased, the increment was most robust for glutamine and alanine. Shorter duration since GC administration and lower IGF-I concentrations independently predicted AA levels. In conclusion, an antenatal course of GC elicited a transient catabolic state encompassing all nutrient substrates, and a temporary drop in IGF-I concentrations. These changes may explain the growth-inhibitory effects of repeated antenatal GC administration. Future research should clarify the role of IGF-I in the protein-catabolic response to GC. (Pediatr Res 62: 295-300, 2007)
\end{abstract}

$\mathrm{I}^{\mathrm{n}}$ ntrauterine growth is driven by the availability of oxygen and nutrient substrates (glucose, FFA, and AA), and by the endocrine and intratissue effects of insulin, IGF-I and IGF-II, and the IGF-binding proteins (IGFBP) (1). IGFBP-1 acts as a growth-inhibitory factor $(2,3)$, presumably because the formation of IGF-I:IGFBP-1 complexes reduces free IGF-I concentrations (4).

Repeated antenatal courses of betamethasone or dexamethasone-i.e. GC that are not inactivated by the fetoplacental $11 \beta$-hydroxysteroid dehydrogenase-unequivocally reduce morbidity in preterm neonates but have a mildly detrimental effect on growth (5-8). In addition, antenatal GC may increase the risk of developing the metabolic syndrome in adult life $(9,10)$. But the underlying mechanisms are not well understood. GC stimulated proteolysis (11) and lipolysis (12) in adults, and proteolysis in sheep fetuses (13). In adults, these catabolic responses are mediated in large part by IR (14); also in preterm neonates, we documented that a course of betamethasone induced a transient increase in IR, as suggested by

Received January 11, 2007; accepted March 30, 2007.

Correspondence: J. Verhaeghe, M.D., Ph.D., Department of Obstetrics and Gynecology, U.Z. Gasthuisberg, Herestraat 49, 3000 Leuven, Belgium; e-mail: johan. verhaeghe@uz.kuleuven.be

Supported by Fonds voor Wetenschappelijk Onderzoek-Vlaanderen (Belgium), grant G.0221.03, and Katholieke Universiteit Leuven, Onderzoekstoelage OT/02/48. the HOMA index (15). Another potential link is the IGFIGFBP axis. Dexamethasone treatment in preterm neonates slightly repressed IGF-I concentrations (16). In addition, the IGFBP-1 promoter contains a GC response element (17) and dexamethasone treatment in rat dams caused IUGR and upregulated fetal liver IGFBP-1 expression (18). It is well established that IGF-I is an anabolic hormone in the fetus (19-21).

The aim of the current study was to investigate the effect of recent antenatal GC exposure on nutrient substrate (glucose, FFA, AA) levels and insulin, IGF-I and IGFBP-1 concentrations at birth.

\section{SUBJECTS AND METHODS}

Subjects. The study was approved by the K.U. Leuven faculty of medicine ethical committee. We collected 140 clean UV blood samples at birth from singleton pregnancies $<38 \mathrm{wk}$ GA. The samples were centrifuged as rapidly as possible, and the plasma was aliquoted and stored at $-80^{\circ} \mathrm{C}$. Exclusion criteria were pregestational or gestational diabetes mellitus, and any documented fetal abnormality (anatomic, chromosomal, infectious). The samples were collected between October 2004 and July 2006 whenever technically possible and clinically available. The parents gave oral informed consent, and they were reassured that no DNA was to be extracted, and that the plasma sample would be discarded after completing the measurements described below. The current series contained no samples analyzed and reported on previously $(2,3,15,22)$.

The primary reasons for delivery were spontaneous preterm labor or ruptured membranes $(n=54)$; antepartum hemorrhage $(n=11)$; hypertensive disease ( $n=53$, of 57 mothers with hypertension; 39 mothers had preeclampsia); IUGR without hypertension but related to smoking or abnormal uteroplacental Dopplers $(n=8)$; intrahepatic cholestasis of pregnancy $(n=8)$, inflammatory bowel disease $(n=3)$, or brain tumor $(n=1)$; and poor obstetric history $(n=2)$. Delivery was by cesarean section for 87 newborns, and 72 newborns had been exposed to labor. Ninety-one newborns had received one course of antenatal GC, which consisted of two intramuscular injections of $12 \mathrm{mg}$ betamethasone (Celestone, Schering-Plough, Kenilworth, $\mathrm{NJ}$ ) in 88 fetuses, and two intramuscular injections of $10 \mathrm{mg}$ dexamethasone (Aacidexam, Organon, Oss, The Netherlands) in three fetuses, 12 or $24 \mathrm{~h}$ apart. The time between the last injection and birth was recorded and varied between 1 and $1358 \mathrm{~h}$ (median: $51 \mathrm{~h}, 10 \mathrm{th}-90$ th percentiles: 4-583 h). Blood gases ( $\mathrm{pH}, \mathrm{PO}_{2}, \mathrm{O}_{2}$ saturation, $\mathrm{PCO}_{2}, \mathrm{HCO}_{3}^{-}$, and base deficit) were measured in heparin-containing syringes from both UA and UV within minutes after birth in a ABL 700 Analyzer (Radiometer Medical A/S, Brønshøj, Denmark).

Assays. Plasma aliquots for AA analysis were batched in runs of eight samples. After deproteinization of samples in 5\% 5-sulphosalicylic acid, AA were measured on a Biochrom 20 Plus AA analyzer (Amersham Pharmacia Biotech, Roosendaal, The Netherlands) by cation-exchange chromatography with lithium citrate-based buffers, following the manufacturer's protocol for accelerated analysis of physiologic fluids. The AA was derivatized with

Abbreviations: AA, amino acid(s); BW, birth weight; GC, glucocorticoid; HOMA, homeostasis model assessment; IGFBP-1, IGF-binding protein-1; IR, insulin resistance; UA, umbilical artery; UV umbilical vein 
ninhydrin in an in-line reactor, and the color yield analyzed at 570 and 440 $\mathrm{nm}$. Results were quantified using an internal standard (2,4-diaminobutyric acid), and calibration with Sigma Chemical Co. (St. Louis, MO) AA mixtures (A6407 acid and neutral AA mixture, and A6282 basic AA mixture). Nineteen AA were assayed: alanine, arginine, asparagine, aspartate, citrulline, cystine, glutamine, glycine, isoleucine, leucine, lysine, methionine, ornithine, phenylalanine, proline, serine, threonine, tyrosine, and valine. FFA was measured enzymatically by the NEFA C assay (Wako, Neuss, Germany), which has a coefficient of variation of $\leq 2.7 \%$. Glucose was measured by the glucoseoxidase method with a YSI 2300 Stat Plus Glucometer (YSI Inc., Yellow Springs, $\mathrm{OH}$ ); coefficient of variation is $1.2 \%$. Insulin was measured by RIA, with recombinant human insulin as the standard and a rabbit antiserum, and a detection limit of $2.5 \mu \mathrm{U} / \mathrm{mL}$ ( $15 \mathrm{pmol} / \mathrm{L}$ ) (15). IGF-I was measured by RIA (22) after eluting the samples on Econo-Pac columns (Econo-Pac ${ }^{\circledR}$, Bio-Rad Laboratories, Richmond, CA), as previously described in detail (23). This extraction was performed to maximally remove the IGFBP from the specimens, since plasma from small-for-GA newborns may contain very high IGFBP-1 levels (3). IGF-I values obtained by a comparable method correlated highly with those obtained after acid gel filtration, the gold standard extraction method (24). IGFBP-1 was measured by RIA, previously described in detail (25). Insulin, IGF-I, and IGFBP-1 measurements were performed in duplicate; the average of the duplicate results was used for data analysis.

Data analysis. We used the NCSS software, version 2004 (Kaysville, UT). $\mathrm{BW} z$ score was calculated as (BW - mean BW at a given GA)/BW SD for that GA, with mean and SD values obtained from Flemish charts derived from more than 429,000 births (3). The HOMA-IR index was computed as [insulin $(\mathrm{mU} / \mathrm{L}) *$ glucose $(\mathrm{mmol} / \mathrm{L})] / 22.5(15)$. We log-transformed the data for statistical analysis when the D'Agostino Omnibus test rejected normal data distribution.

We used $\chi^{2}$ tests for comparisons of categorical variables, and two-sample $t$ tests and one-way ANOVA for comparisons of continuous variables between two groups or more than two groups, respectively. One-way ANOVA was followed, if $p<0.05$, by Tukey-Kramer's post hoc multiple-comparison test to compare individual groups. We also used two-way (GLM) ANOVA to test for interactions between two factor variables. Regression analyses included pair-wise Spearman rank correlations and multiple regression (robust regression using Huber's method).

\section{RESULTS}

Effects of antenatal GC exposure. In the GC-exposed newborns $(n=91)$, we found a strong correlation (controlled for labor) between the time (in hours) since the last administration and UV concentrations of total AA $(r=-0.618)$, FFA $(r=-0.335)$, glucose $(r=-0.296)$, insulin $(r=-0.569)$, HOMA-IR $(r=-0.537)$, and IGF-I $(r=0.315)$ (all $p<$ $0.005)$; there was also a marginal correlation with IGFBP-1 $(r=0.211, p=0.046)$. A correlation was observed for all individual AA ( $r$ between -0.224 and $-0.633, p<0.034$ ), except lysine $(p=0.83)$.

We then stratified the GC-exposed newborns into four groups $(<24 \mathrm{~h}, 24-48 \mathrm{~h}, 49-168 \mathrm{~h}$, and $>168 \mathrm{~h})$ and compared the data with non-GC-exposed newborns (Fig. 1). FFA and glucose concentrations were elevated only in newborns exposed to $\mathrm{GC}<24 \mathrm{~h}$ before birth, whereas total AA, insulin (data not shown) and HOMA-IR were increased in those exposed within the last $48 \mathrm{~h}$; IGF-I concentrations were reduced $\leq 48 \mathrm{~h}$ after the last $\mathrm{GC}$ administration. We found no difference in IGFBP-1 concentrations $(p=0.113$, data not shown). To follow the pattern of normalization after $48 \mathrm{~h}$ in more detail for total AA, insulin, HOMA-IR, and IGF-I, we compared these parameters in newborns last exposed to GC $<24$ h, 24-48 h, 49-72 h, 73-96 h, and 97-120 h before birth ( $n=31,14,9,5$, and 5, respectively), by one-way ANOVA. Whereas total AA and insulin declined gradually after $48 \mathrm{~h}$ (significant difference by Tukey-Kramer's test between the

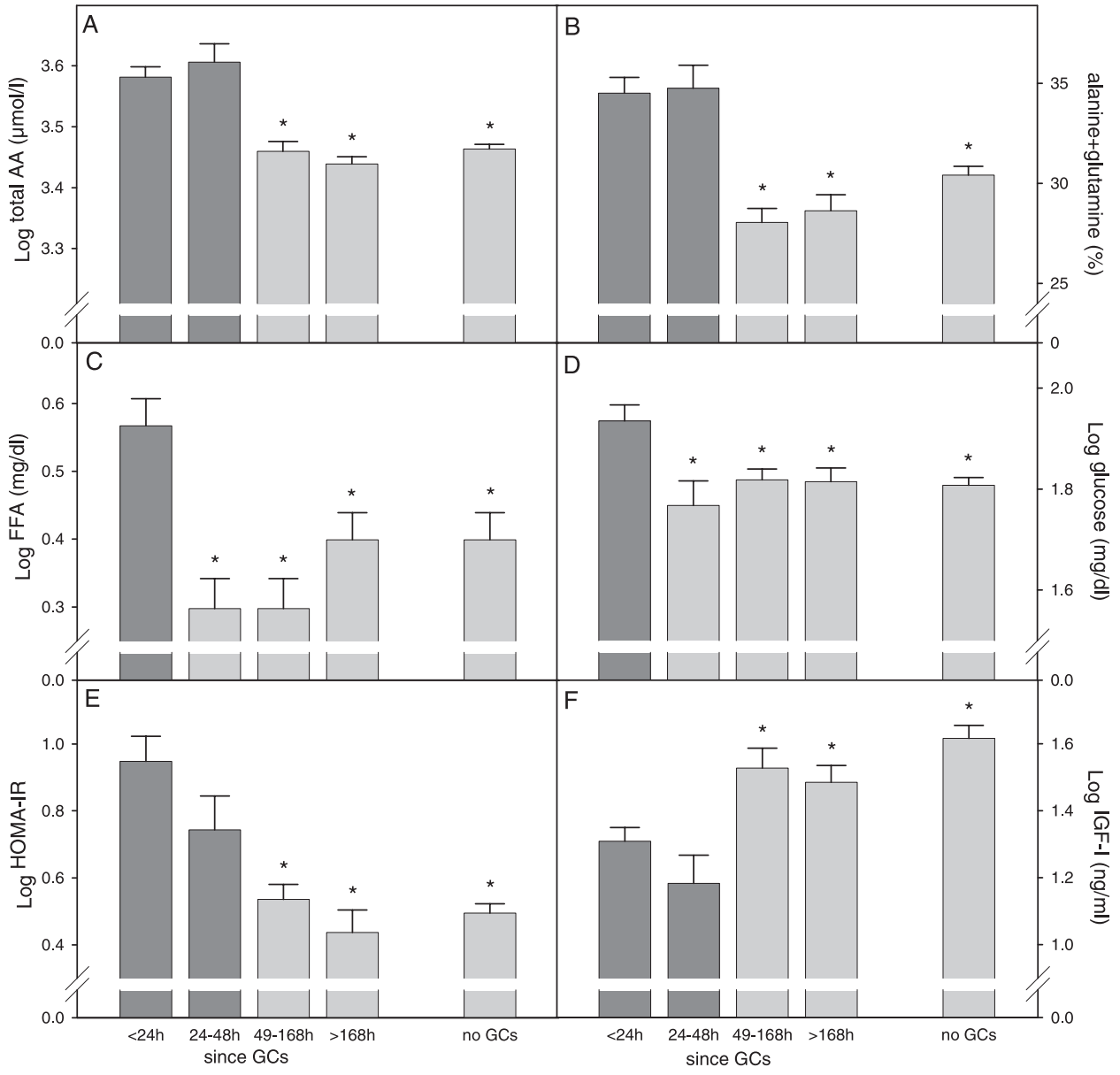

Figure 1. Transient but generalized catabolic effect after antenatal GC exposure. The newborns were stratified according to the time since the last GC administration: $<24$ h $(n=31), 24-48$ h $(n=14), 49-168$ h $(n=22),>168$ h $(n=24)$, or no GC $(n=49)$. We show the UV total AA concentrations (sum of 19 AA in $\mu \mathrm{mol} / \mathrm{L}$ ) $(A)$, the relative alanine + glutamine abundance $(B)$, FFA $(C)$ and glucose $(D)$ concentrations, the HOMA-IR index $(E)$, and IGF-I concentrations $(F)$. We used one-way ANOVA to analyze the results. All analyses showed a $p$ value $<0.001$; the $F$ variance ratio was 23.96 for total AA, 16.68 for alanine + glutamine, 5.54 for glucose, 6.07 for FFA, 14.42 for HOMA-IR, and 10.92 for IGF-I. The data are shown as means \pm SEM. Groups denoted by an asterisk are significantly different from the first group $(<24 \mathrm{~h})$, according to Tukey-Kramer's multiple-comparison test. 
Table 1. Individual AA in UV plasma ( $\mu \mathrm{mol} / \mathrm{L})$ in relation to antenatal GC administration

\begin{tabular}{|c|c|c|c|c|}
\hline & $\begin{array}{c}\leq 48 \mathrm{~h} \\
\text { after GC } \\
(n=45)\end{array}$ & $\begin{array}{c}>48 \mathrm{~h} \\
\text { after GC } \\
(n=46)\end{array}$ & $\begin{array}{c}\text { No GC } \\
(n=49)\end{array}$ & $F$ \\
\hline Essential AA* & $1482(40)^{\mathrm{a}}$ & $1273(32)^{b}$ & $1218(22)^{\mathrm{b}}$ & 18.37 \\
\hline Arginine* ${ }^{*} \div$ & $102(6)^{a}$ & $78(4)^{b}$ & $69(4)^{\mathrm{b}}$ & 10.12 \\
\hline Isoleucine* & $82(2)^{\mathrm{a}}$ & $64(2)^{b}$ & $58(2)^{\mathrm{b}}$ & 30.95 \\
\hline Leucine* & $142(5)^{\mathrm{a}}$ & $117(4)^{\mathrm{b}}$ & $107(3)^{\mathrm{b}}$ & 15.66 \\
\hline Lysine** & $431(11)^{\mathrm{a}}$ & $417(12)^{\mathrm{a}, \mathrm{b}}$ & $390(9)^{b}$ & 3.68 \\
\hline Methionine* & $41(2)^{a}$ & $27(0.9)^{\mathrm{b}}$ & $28(0.9)^{\mathrm{b}}$ & 34.19 \\
\hline Phenylalanine* & $103(5)^{\mathrm{a}}$ & $84(3)^{b}$ & $85(2)^{\mathrm{b}}$ & 10.86 \\
\hline Threonine* & $329(18)^{\mathrm{a}}$ & $256(10)^{\mathrm{b}}$ & $269(9)^{b}$ & 9.14 \\
\hline Valine* & $253(7)^{a}$ & $231(6)^{b}$ & $212(4)^{b}$ & 12.07 \\
\hline Nonessential AA* & $2352(114)^{\mathrm{a}}$ & $1452(39)^{\mathrm{b}}$ & $1590(37)^{\mathrm{b}}$ & 52.79 \\
\hline Alanine* & $654(37)^{\mathrm{a}}$ & $374(16)^{\mathrm{b}}$ & $412(16)^{b}$ & 36.42 \\
\hline Asparagine* & $58(3)^{\mathrm{a}}$ & $35(1.3)^{\mathrm{b}}$ & $38(1.3)^{\mathrm{b}}$ & 34.92 \\
\hline Aspartate** & $13(1.3)^{\mathrm{a}}$ & $8(0.6)^{\mathrm{b}}$ & $11(2)^{b}$ & 4.71 \\
\hline Cystine $\dagger$ & $20(4)$ & $9(1.4)$ & $13(2)$ & 2.94 \\
\hline Glutamine* & $752(41)^{\mathrm{a}}$ & $436(15)^{b}$ & $486(14)^{b}$ & 50.07 \\
\hline Glycine* & $334(16)^{\mathrm{a}}$ & $221(7)^{b}$ & $251(8)^{c}$ & 25.45 \\
\hline Proline* & $258(15)^{\mathrm{a}}$ & $167(5)^{b}$ & $171(6)^{b}$ & 35.96 \\
\hline Serine* & $173(7)^{\mathrm{a}}$ & $129(4)^{\mathrm{b}}$ & $136(3)^{\mathrm{b}}$ & 21.12 \\
\hline Tyrosine* & $90(3)^{a}$ & $73(3)^{\mathrm{b}}$ & $73(2)^{b}$ & 11.83 \\
\hline \multicolumn{5}{|l|}{ Urea cycle AA } \\
\hline Citrulline* & $20(1.2)^{\mathrm{a}}$ & $16(0.5)^{\mathrm{b}}$ & $18(0.6)^{\mathrm{b}}$ & 8.66 \\
\hline Ornithine* & $133(6)^{\mathrm{a}}$ & $102(5)^{b}$ & $109(4)^{b}$ & 10.81 \\
\hline
\end{tabular}

Data (back-transformed) are presented as means (SEM). We used one-way ANOVA to analyze the results: $* p<0.001$, $* * p<0.05, \dagger p=0.056$; we also show the $F$ variance ratio. Groups denoted by a different letter in superscript $\left({ }^{\mathrm{a}, \mathrm{b}, \mathrm{c}}\right)$ are significantly different from one another, according to Tukey-Kramer's multiple-comparison test. $\$$ Arginine is believed to be an essential AA during development (26).

$\leq 48 \mathrm{~h}$ groups and the $97-120 \mathrm{~h}$ group), IGF-I concentrations rose more abruptly after $48 \mathrm{~h}$, with a significant difference between the $24-48 \mathrm{~h}$ and $49-72 \mathrm{~h}$ groups (data not shown).

Because the main metabolic differences were thus observed in the newborns that received GC $\leq 48 \mathrm{~h}$ versus $>48 \mathrm{~h}$ before birth, in all further analyses only two groups of GC-exposed newborns were retained ( $\leq 48$ and $>48$ h). In Table 1 , we show that the levels of all AA were increased in recently GC-exposed newborns ( $\leq 48 \mathrm{~h}$ ) compared with the other two groups, whereas there was no difference between newborns who received GC $>48 \mathrm{~h}$ before birth and those who received no GC. The increase in the recently GC-exposed group was more pronounced for the nonessential AA than for the essential AA, as indicated by the higher $F$ variance ratios. Looking at the individual AA, the largest relative and absolute differences were observed for glutamine and alanine. The relative alanine + glutamine abundance (percentage of total AA) was inversely correlated with time since last GC $(r=-0.524$; $p<$ 0.001; see also Fig. 1B).

The metabolic differences between newborns exposed to $\mathrm{GC} \leq 48 \mathrm{~h}$ versus $>48 \mathrm{~h}$ before birth were not the result of major differences in clinical characteristics (Table 2). There were slight differences in GA and head circumference, but $\mathrm{BW}, \mathrm{BW} z$ score, and length were comparable. In contrast, non-GC-exposed newborns were clearly different in GA and size at birth, as would be expected. Regarding blood gases at birth, the recently GC-exposed group had lower base-deficit values in both UA and UV (not shown) than those exposed $>48 \mathrm{~h}$ before, but there was no difference among the groups in $\mathrm{pH}, \mathrm{HCO}_{3}^{-}, \mathrm{PCO}_{2}$ or $\mathrm{PO}_{2}$ values in either UA or UV, or the arteriovenous $\mathrm{PO}_{2}$ difference (data not shown).

Interactions with size at birth. We used two-way ANOVA to assess whether the metabolic effects of time since last GC administration ( $\leq 48 \mathrm{~h}$ versus $>48 \mathrm{~h})$ interacted with sex or BW ( $z$ score $<0$ versus $>0$ ). We found no (time since GC $\times$ sex)-interaction at the $p<0.05$ levels for any of the metabolic variables (data not shown). But Table 3 demonstrates a highly significant (time since $\mathrm{GC} \times \mathrm{BW}$ )-interaction for the $\mathrm{AA}$ response. Because of this interaction, we went on to compare the AA levels of the four individual groups by one-way ANOVA: this analysis confirmed that the surge in AA after recent $\mathrm{GC}$ exposure was greater in newborns with $\mathrm{BW} z$ score $<0$ (Fig. 2A). Examining individual AA, we found an (time since $\mathrm{GC} \times \mathrm{BW}$ ) interaction at the $p<0.05$ levels for two essential AA (methionine and threonine), seven nonessential AA (alanine, asparagine, glutamine, glycine, proline, serine, and tyrosine), and ornithine (data not shown). Whereas newborns with BW $z$ score $<0$ had lower glucose, HOMA-IR, and IGF-I than those with BW $z>0$, there was no (time since $\mathrm{GC} \times \mathrm{BW}$ )-interaction for FFA, glucose, insulin, HOMA-IR, IGF-I, or IGFBP-1 (Table 3).

Nutrient responses in relation to HOMA-IR and IGF-I. The HOMA-IR index was correlated with total AA $(r=$

Table 2. Clinical characteristics according to the time elapsed since the last GC exposure

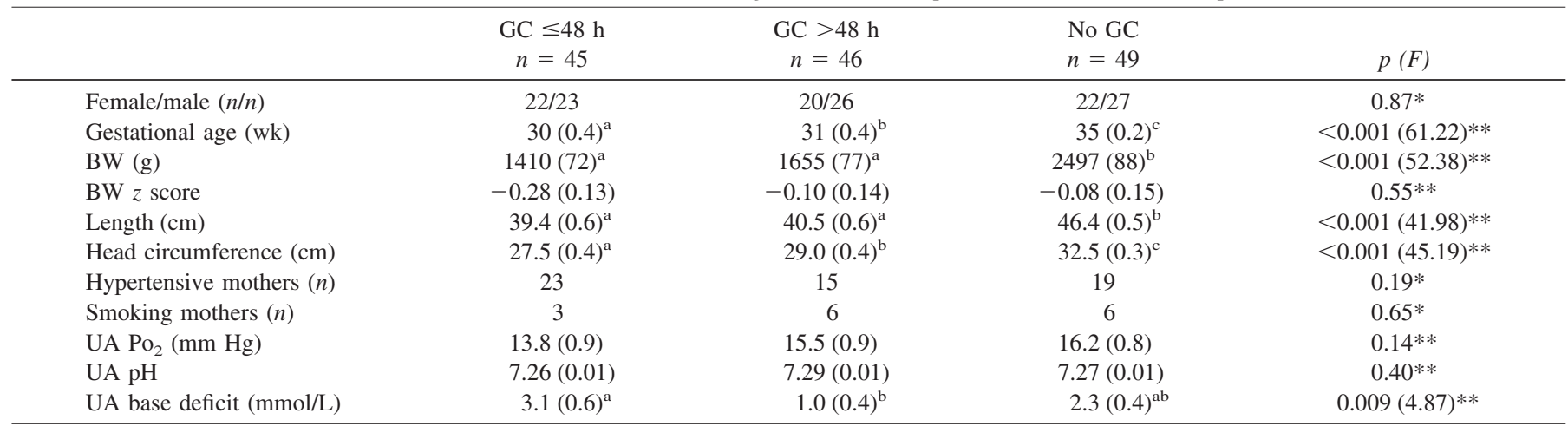

The data are shown as means (SEM). * Statistical analysis by $\chi^{2}$ test. ** Statistical analysis by one-way ANOVA $(F$ variance ratio is shown if $p<0.05)$; if $p<0.05$, Tukey-Kramer's multiple-comparison test was used to compare individual groups, with differences at the $p<0.05$ level shown by a different letter in superscript ${ }^{\mathrm{a}, \mathrm{b}, \mathrm{c}}$. 
Table 3. Two-way ANOVA examining the interaction between time since last GC administration and size at birth on nutrient and hormone concentrations (GC-exposed newborns only, $n=91$ )

\begin{tabular}{llll}
\hline & $\begin{array}{c}\text { Term 1: time since GC } \\
(\leq 48 \mathrm{~h} v s>48 \mathrm{~h})\end{array}$ & $\begin{array}{c}\text { Term 2: BW } z \text { score } \\
(<0 \text { vs }>0)\end{array}$ & Interaction between terms \\
\hline AA & & & $p<0.001(F=12.00)$ \\
$\quad$ Total & $p<0.001(F=62.73)$ & $p=0.008(F=7.36)$ & $p=0.017(F=5.95)$ \\
Essential & $p<0.001(F=16.57)$ & $p=0.39$ & $p=0.001(F=10.99)$ \\
$\quad$ Nonessential & $p<0.001(F=81.22)$ & $p<0.001(F=18.46)$ & $p=0.095$ \\
FFA & $p=0.008(F=7.37)$ & $p=0.66$ & $p=0.39$ \\
Glucose & $p=0.018(F=5.76)$ & $p=0.007(F=7.61)$ & $p=0.71$ \\
Insulin & $p<0.001(F=39.43)$ & $p=0.011(F=6.83)$ & $p=0.92$ \\
HOMA-IR & $p<0.001(F=33.39)$ & $p<0.001(F=27.19)$ & $p=0.60$ \\
IGF-I & $p<0.001(F=18.89)$ & $p=0.060$ & $p=0.47$ \\
IGFBP-1 & $p=0.24$ & & \\
\hline
\end{tabular}

We show the $F$ variance ratio if $p<0.05$.

0.349; $p<0.001)$ and FFA concentrations $(r=0.238, p=$ 0.025 ) in GC-exposed newborns; in those exposed $\leq 48 \mathrm{~h}$ before birth, HOMA-IR was also correlated with FFA $(r=$ $0.327, p=0.033)$ but not with AA concentrations $(p=0.24)$. In contrast, IGF-I concentrations were inversely correlated with AA $(r=-0.306, p=0.003)$ but not FFA $(p=0.95)$ or glucose $(p=0.20)$ levels; in those exposed to $\mathrm{GC} \leq 48 \mathrm{~h}$ before birth, IGF-I remained a correlate of total AA $(r=$

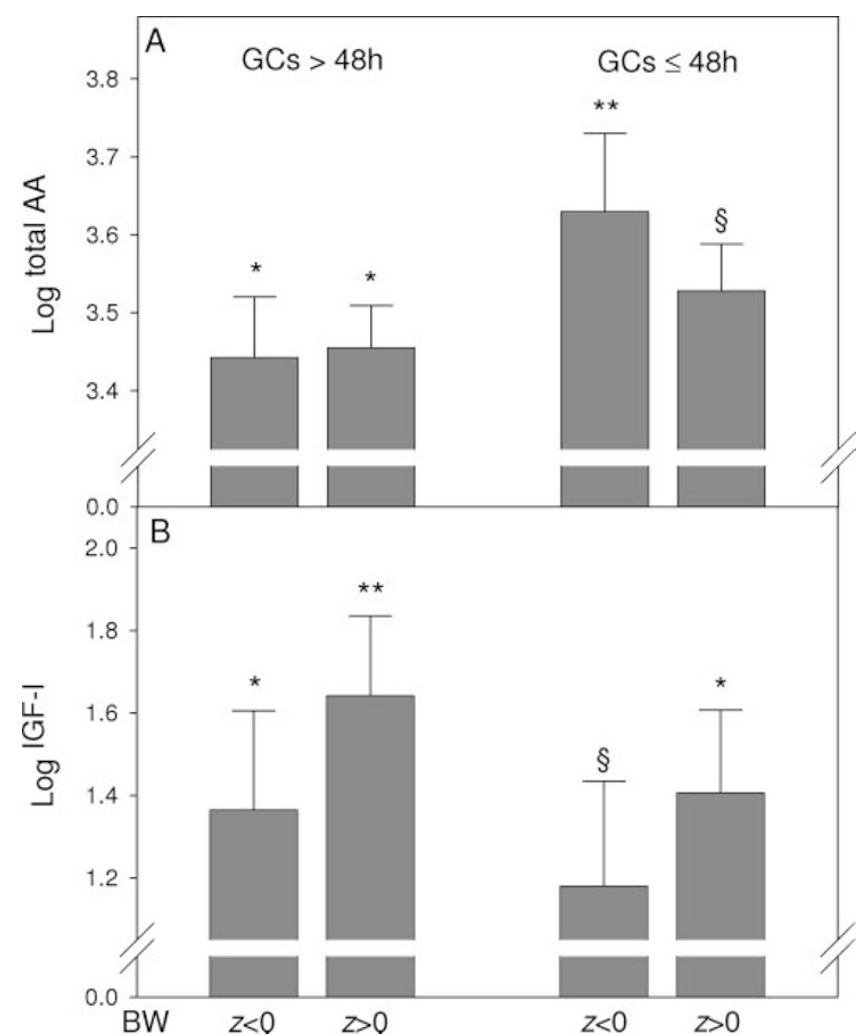

Figure 2. AA and IGF-I concentrations according to duration since last GC administration and size at birth. We show the UV AA concentrations (sum of $19 \mathrm{AA}$ in $\mu \mathrm{mol} / \mathrm{L})(A)$ and IGF-I concentrations $(B)$ in newborns who received GC $>48$ h before birth and had a BW $z$ score $<0(n=23)$ or $>0$ $(n=23)$, and newborns who received GC $\leq 48 \mathrm{~h}$ before birth and had a BW $z$ score $<0(n=27)$ or $>0(n=18)$. We used one-way ANOVA to analyze the results. Both analyses showed a $p$ value $<0.001$; the $F$ variance ratio was 31.08 for total AA and 17.30 for IGF-I. The data are shown as means \pm SEM. Groups denoted by a different symbol (*,**, §) are significantly different from one another, according to Tukey-Kramer's multiple-comparison test.
$-0.335, p=0.025)$, and particularly nonessential AA concentrations $(r=-0.446, p=0.002)$. Figure $2 B$ shows that IGF-I concentrations were lowest in newborns with below average $\mathrm{BW}$ who were recently exposed to $\mathrm{GC}$, i.e. the subgroup with the highest AA levels. We went on to examine whether IGF-I or HOMA-IR improved the prediction of AA levels in GC-exposed newborns conferred by the time since the last administration. In a multiple regression model, shorter time since GC ( $T$ value $=-3.607, p<0.001$, partial $\left.R^{2}=0.130\right)$ and low IGF-I concentrations ( $T$ value $=-3.177$, $p=0.002$, partial $\left.R^{2}=0.104\right)$ were independent predictors of total AA levels (model adjusted $R^{2}=0.241$ ). In counterpart, HOMA-IR was not an independent predictor of AA levels $(p>0.05)$ when added to time since GC (data not shown).

\section{DISCUSSION}

We demonstrated that an antenatal course of GC induced transient nutrient catabolism, with increased glucose, FFA, and AA concentrations for $24-48 \mathrm{~h}$. We also confirmed a transient increase in insulin concentrations and the HOMA-IR index (15), which correlated with nutrient levels. While this suggests a relationship between IR and nutrient catabolism, it remains to be established whether the HOMA-IR index in UV plasma is a valid marker of insulin sensitivity in newborn infants as assessed by gold-standard methodology (e.g. hyperinsulinemic euglycemic clamps). Nonetheless, such mechanism is biologically plausible. Insulin is an anabolic hormone in utero $(21,27)$, whereas GC treatment caused proteolysis in sheep fetuses (13). Also, IR explained a large part of the GC-induced proteolytic response in human adults (14).

The relative hyperglycemia observed in newborns exposed to $\mathrm{GC}<24 \mathrm{~h}$ before birth may well be the result of the rise in maternal glucose levels following GC administration (28). In addition, transplacental passage of GC may affect glucose metabolism in the fetus and neonate by down-regulating glucose disposal in peripheral tissues (29) while stimulating hepatic glucose production, as suggested by experiments in sheep fetuses (30).

Whether the transient drop in IGF-I concentrations after GC administration is a consequence of IR, is uncertain. In sheep fetuses, pancreatectomy reduced circulating IGF-I (31) suggesting that insulin promotes IGF-I secretion, but other sup- 
portive evidence is lacking. The decrement in IGF-I concentrations was observed regardless of BW $z$ score (Fig. 2B); in a recent study that also examined the effect of antenatal betamethasone, there was no effect on IGF-I levels at birth, but the group that received GC $<2$ wk before birth was not subdivided (28). IGF-I is a distinct protein-anabolic hormone in the ovine fetus, stimulating protein synthesis while suppressing proteolysis and AA oxidation (19-21). We found that the time elapsed since the last GC administration and IGF-I independently predicted AA levels. Thus, the endogenously lower IGF-I concentrations in newborns with BW below the mean in combination with the reduction in IGF-I imposed by GC treatment might explain their greater protein-catabolic response. Alternatively, reduced IGF-I in newborns with below average BW could reflect raised endogenous cortisol levels (32), and the combination with exogenous GCs might thus confer a more robust protein-catabolic response. In sheep, growth-retarded fetuses were not only IGF-I deficient but also less sensitive to the actions of exogenous IGF-I (33). Clearly, further research on the role of IGF-I in GC-induced catabolism in fetuses and neonates is mandatory.

Recent GC exposure altered the plasma AA composition. Glutamine and alanine showed the largest increase, compatible with de novo synthesis from other AA, as shown in adults subjected to a hydrocortisone infusion (34). These abundant AA play an important role in fuel regulation. Degradation of AA results in the transfer of amino groups to form glutamate. Glutamate is then converted into glutamine, or its amino group is transferred to pyruvate to form alanine and $\alpha$-ketoglutarate by the catalytic action of alanine aminotransferase (26). Both this enzyme and lactate dehydrogenase produce a biochemical equilibrium between alanine, pyruvate, and lactate in plasma. Thus, conditions that are associated with mitochondrial dysfunction and preferential anaerobic energy production are accompanied by elevated alanine levels. For example, hyperalaninemia was observed in neonates with lactic acidemia caused by a congenital defect in mitochondrial oxidative phosphorylation (35). It would be of interest, therefore, to investigate whether antenatal GC administration results in mitochondrial dysfunction in tissues such as skeletal muscle. In addition, glutamine and alanine are key AA in the regulation of insulin secretion (36), and may be involved-together with glucose-in the GC-induced hyperinsulinemia.

UV FFA concentrations were raised $<24 \mathrm{~h}$ after GC exposure. IR-associated lipolysis is a likely mechanism, given the correlation with HOMA-IR. In adults, GC treatment raised circulating AA (11) and glucose but not FFA (37). Although GC do provoke lipolysis in adults (12), this response is depot-specific, e.g. in subcutaneous abdominal adipose tissue but not in other depots (37). Subcutaneous trunk fat is an important fat compartment in utero (38), which may explain the transient increase in circulating FFA following GC exposure. However, although small-for-GA neonates have less subcutaneous fat than appropriate-for-GA neonates (38), we did not find that the FFA response to GC interacted with $\mathrm{BW}$ $z$ score (Table 3).

The current study may be of relevance in the ongoing debate about the benefits and risks of repeated GC adminis- tration in preterm pregnancies to improve neonatal outcome $(7,8)$ and of "aggressive" dexamethasone treatment in the management of severe preeclampsia (39). Our metabolic data lend support to those favoring a cautious approach, especially in pregnancies accompanied by in utero growth restriction. Further prospective studies should be set up to buttress our results, preferably in pregnancies with a single mode of delivery.

In summary, our data show a generalized catabolic response to antenatal GC that lasted for 24-48 $\mathrm{h}$ after the last administration; in addition, IGF-I levels were suppressed for $48 \mathrm{~h}$. The increment in AA was most pronounced for glutamine and alanine. The surge in AA concentrations was more robust in newborns with $\mathrm{BW}$ below the mean, which may be linked to their endogenously reduced IGF-I concentrations.

\section{REFERENCES}

1. Murphy VE, Smith R, Giles WB, Clifton VL 2006 Endocrine regulation of human fetal growth: the role of the mother, placenta, and fetus. Endocr Rev 27:141-169

2. Verhaeghe J, Billen J, Giudice LC 2001 Insulin-like growth factor-binding protein-1 in umbilical artery and vein of term fetuses with signs suggestive of distress during labor. J Endocrinol 170:585-590

3. Verhaeghe J, Van Herck E, Billen J, Moerman P, Van Assche FA, Giudice LC 2003 Regulation of insulin-like growth factor-I and insulin-like growth factor binding protein-1 in preterm fetuses. Am J Obstet Gynecol 188:485-491

4. Frystyk J, Højlund K, Rasmussen KN, Jørgensen SP, Wildner-Christensen M, Ørskov H 2002 Development and clinical evaluation of a novel immunoassay for the binary complex of IGF-I and IGF-binding protein-1 in human serum. J Clin Endocrinol Metab 87:260-266

5. French NP, Hagan R, Evans SF, Godfrey M, Newnham JP 1999 Repeated antenatal corticosteroids: size at birth and subsequent development. Am J Obstet Gynecol 180:114-121

6. Banks BA, Cnaan A, Morgan MA, Parer JT, Merrill JD, Ballard PL, Ballard RA 1999 Multiple courses of antenatal corticosteroids and outcome of premature neonates. North American Thyrotropin-Releasing Hormone Study Group. Am J Obstet Gynecol 181:709-717

7. Crowther CA, Haslam RR, Hiller JE, Doyle LW, Robinson JS, Australasian Collaborative Trial of Repeat Doses Steroids (ACTORDS) Study Group 2006 Neonatal respiratory distress syndrome after repeat exposure to antenatal corticosteroids: a randomised controlled trial. Lancet 367:1913-1919

8. Wapner RJ, Sorokin Y, Thom EA, Johnson F, Dudley DJ, Spong CY, Peaceman AM, Leveno KJ, Harper M, Caritis SN, Miodovnik M, Mercer B, Thorp JM, Moawad A, O'Sullivan MJ, Ramin S, Carpenter MW, Rouse DJ, Sibai B, Gabbe SG National Institute of Child Health and Human Development Maternal Fetal Medicine Units Network 2006 Single versus weekly courses of antenatal corticosteroids: evaluation of safety and efficacy. Am J Obstet Gynecol 195:633-642

9. McMillen IC, Robinson JS 2005 Developmental origins of the metabolic syndrome: prediction, plasticity, and programming. Physiol Rev 85:571-633

10. Dalziel SR, Walker NK, Parag V, Mantell C, Rea HH, Rodgers A, Harding JE 2005 Cardiovascular risk factors after antenatal exposure to betamethasone: 30-year follow-up of a randomised controlled trial. Lancet 365:1856-1862

11. Simmons PS, Miles JM, Gerich JE, Haymond MW 1984 Increased proteolysis: an effect of increases in plasma cortisol within the physiologic range. J Clin Invest 73:412-420

12. Divertie GD, Jensen MD, Miles JM 1991 Stimulation of lipolysis in humans by physiological hypercortisolemia. Diabetes 40:1228-1232

13. Milley JR 1995 Effects of increased cortisol concentration on ovine fetal leucine kinetics and protein metabolism. Am J Physiol 268:E1114-E1122

14. Louard RJ, Bhushan R, Gelfand RA, Barrett EJ, Sherwin RS 1994 Glucocorticoids antagonize insulin's antiproteolytic action on skeletal muscle in humans. J Clin Endocrinol Metab 79:278-284

15. Verhaeghe J, van Bree R, van Herck E, Coopmans W 2005 Exogenous corticosteroids and in utero oxygenation modulate indices of fetal insulin secretion. J Clin Endocrinol Metab 90:3449-3453

16. Bloomfield FH, Knight DB, Breier BH, Harding JE 2001 Growth restriction in dexamethasone-treated preterm infants may be mediated by reduced IGF-I and IGFBP-3 plasma concentrations. Clin Endocrinol (Oxf) 54:235-242

17. Suwanichkul A, Allander SV, Morris SL, Powell DR 1994 Glucocorticoids and insulin regulate expression of the human gene for insulin-like growth factor-binding protein-1 through proximal promoter elements. J Biol Chem 269:30835-30841

18. Price WA, Stiles AD, Moats-Staats BM, D'Ercole AJ 1992 Gene expression of insulin-like growth factors (IGFs), the type 1 IGF receptor, and IGF-binding proteins in dexamethasone-induced fetal growth retardation. Endocrinology 130:1424-1432

19. Harding JE, Liu L, Evans PC, Gluckman PD 1994 Insulin-like growth factor 1 alters feto-placental protein and carbohydrate metabolism in fetal sheep. Endocrinology 134:1509-1514 
20. Liechty EA, Boyle DW, Moorehead H, Lee WH, Yang XL, Denne SC 1999 Glucose and amino acid kinetic response to graded infusion of rhIGF-I in the late gestation ovine fetus. Am J Physiol 277:E537-E543

21. Shen W, Wisniowski P, Ahmed L, Boyle DW, Denne SC, Liechty EA 2003 Protein anabolic effects of insulin and IGF-I in the ovine fetus. Am J Physiol 284:E748E756

22. Verhaeghe J, Van Bree R, Van Herck E, Laureys J, Bouillon R, Van Assche FA 1993 C-peptide, insulin-like growth factors I and II, and insulin-like growth factor binding protein-1 in umbilical cord serum: correlations with birth weight. Am J Obstet Gynecol 169:89-97

23. Verhaeghe J, Van Herck E, van Bree R, Moermans K, Bouillon R 1997 Decreased osteoblast activity in spontaneously diabetic rats: in vivo studies on the pathogenesis. Endocrine 7:165-175

24. Mohan S, Baylink DJ 1995 Development of a simple valid method for the complete removal of insulin-like growth factor (IGF)-binding proteins from IGFs in human serum and other biological fluids: comparison with acid-ethanol extraction and C18 Sep-Pak separation. J Clin Endocrinol Metab 80:637-647

25. Verhaeghe J, Coopmans W, Van Herck E, Van Schoubroeck D, Deprest JA, Witters I 1999 IGF-I, IGF-II, IGF-binding protein 1, and C-peptide in second trimester amniotic fluid are dependent on gestational age but do not predict weight at birth. Pediatr Res 46:101-108

26. Lehninger AL, Nelson DL, Cox MM 2000 Principles of Biochemistry. Worth, New York, pp 506-538

27. Fowden AL 1993 Insulin deficiency: effects on fetal growth and development. J Paediatr Child Health 29:6-11

28. Ahmad I, Beharry KD, Valencia AM, Cho S, Guajardo L, Nageotte MP, Modanlou HD 2006 Influence of a single course of antenatal betamethasone on the maternalfetal insulin-IGF-GH axis in singleton pregnancies. Growth Horm IGF Res 16:267275
29. Tappy L, Randin D, Vollenweider P, Vollenweider L, Paquot N, Scherrer U, Schnetter P, Nicod P, Jéquier E 1994 Mechanisms of dexamethasone-induced insulin resistance in healthy humans. J Clin Endocrinol Metab 79:1063-1069

30. Franko KL, Giussani DA, Forhead AJ, Fowden AL 2007 Effects of dexamethasone on the glucogenic capacity of fetal, pregnant, and non-pregnant adult sheep. J Endocrinol 192:67-73

31. Gluckman PD, Butler JH, Comline R, Fowden A 1987 The effects of pancreatectomy on the plasma concentrations of insulin-like growth factors 1 and 2 in sheep fetuses. J Dev Physiol 9:79-88

32. Cianfarani S, Germani D, Rossi L, Argirò G, Boemi S, Lemon M, Holly JM, Branca F 1998 IGF-I and IGF-binding protein-1 are related to cortisol in human cord blood. Eur J Endocrinol 138:524-529

33. Jensen EC, Harding JE, Bauer MK, Gluckman PD 1999 Metabolic effects of IGF-I in the growth retarded fetal sheep. J Endocrinol 161:485-494

34. Darmaun D, Matthews DE, Bier DM 1988 Physiological hypercortisolemia increases proteolysis, glutamine, and alanine production. Am J Physiol 255:E366-E373

35. Rubio-Gozalbo ME, Sengers RC, Trijbels JM, Doesburg WH, Janssen AJ, Verbeek AL, Smeitink JA 2000 A prognostic index as diagnostic strategy in children suspected of mitochondriocytopathy. Neuropediatrics 31:114-121

36. Newsholme P, Brennan L, Bender K 2006 Amino acid metabolism, $\beta$-cell function, and diabetes. Diabetes 55:S39-S47

37. Gravholt CH, Dall R, Christiansen JS, Møller N, Schmitz O 2002 Preferential stimulation of abdominal subcutaneous lipolysis after prednisolone exposure in humans. Obes Res 10:774-781

38. Harrington TA, Thomas EL, Frost G, Modi N, Bell JD 2004 Distribution of adipose tissue in the newborn. Pediatr Res 55:437-441

39. Martin JN, Rose CH, Briery CM 2006 Understanding and managing HELLP syndrome: the integral role of aggressive glucocorticoids for mother and child. Am J Obstet Gynecol 195:914-934 